Int. J. Electrochem. Sci., 13 (2018) 10233 - 10246

\title{
Synthesis, Thermal Stability and Electrocatalytic Activities of meso-tetrakis (5-bromothiophen-2-yl) Porphyrin and Its Cobalt and Copper Complexes
}

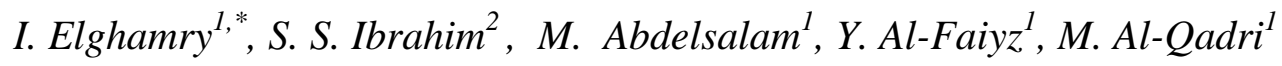 \\ ${ }^{1}$ Department of Chemistry, King Faisal University, P. O. Box 380 Al-Hofuf, 31982 Al-Ahsa, Saudi \\ Arabia. \\ ${ }^{2}$ Department of Physics, King Faisal University, P. O. Box 380 Al-Hofuf, 31982 Al-Ahsa, Saudi \\ Arabia. \\ *E-mail: ielghamry@kfu.edu.sa, elghamry@hotmail.com
}

doi: $10.20964 / 2018.11 .70$

Received: 11 July 2018 / Accepted: 12 September 2018 / Published: 1 October 2018

Linearly $p i$-extended thienyl porphyrin namely 5,10,15,20 tetrakis (5-bromothiophen-2-yl) porphyrin, and its cobalt and copper complexes were synthesized in good and quantitative yields respectively. The chemical structure of the synthesized porphyrins was confirmed by spectroscopic techniques (FT-IR, NMR, MS, and UV-Vis). Additionally, the thermal gravimetric analysis (TGA) was measured to investigate the high-temperature stability of the porphyrins. Subsequently, the porphyrins were used as electrocatalysts for the oxygen evolution reaction (OER) in $1 \mathrm{M} \mathrm{KOH}$. The cobalt-porphyrin complex showed the best performance in term of a low band gap value and a high catalytic activity with good stability towards the OER.

Keywords: Metalloporphyrin; Thermal stability; Electrocatalytic activity; Oxygen evolution reaction.

\section{FULL TEXT}

(C) 2018 The Authors. Published by ESG (www.electrochemsci.org). This article is an open access article distributed under the terms and conditions of the Creative Commons Attribution license (http://creativecommons.org/licenses/by/4.0/). 